\title{
Children's images of beauty: environmental influences on aesthetic preferences
}

\author{
7966 words including Abstract and References
}

\begin{abstract}
This article reports on a recent study that explored children's aesthetic preferences. Authors of previous studies in this area have concluded children have a relatively narrow range of preferences based on judgments about their responses to images. In other contexts, researchers have investigated children's perspectives on their environments and created opportunities for them to take photographs in response to research tasks. This study is the first to draw on both approaches in order to develop a clearer understanding of children's aesthetic preferences. 51 children in two primary schools were asked to find and photograph images to represent their perceptions of beauty. In order to investigate whether or how children's environments influenced their preferences, the schools were located in contrasting urban and rural areas. The article explores several contrasts between the two sets of images and offers explanations for these contrasts. It suggests that previous studies may have underestimated the diversity of children's aesthetic preferences and that social, cultural and environmental factors may explain the differences between children's aesthetic preferences. The article concludes that both researchers and teachers could adopt similar methods to develop our understanding of children's perspectives, identities and experiences.
\end{abstract}

\section{Introduction}

The role of images in children's lives is rapidly changing. Until recently, the images children encountered were those specifically targeted at them through books and other media. Now, digital technologies enable children to locate, create and share images in greater numbers, in a wider range of contexts and often independent of adult support. As educators, we need to understand more about what children find interesting, engaging and appealing about these images, and to explore their potential for children as a means of investigating and expressing those aspects of their lives that are meaningful to them.

This article reports on a recent study that explored children's perceptions of beauty. Beauty is a marginalised theme in art and education and widely regarded as a problematic notion in a range of cultural contexts (Beech 2009; Hickey 2009; Winston 2010). Art educators seeking to raise children's levels of engagement with art tend to be resistant to the concept of beauty, associating it with the passive appreciation of art rather than active engagement with the subject (Steers 2014). Previous studies of children's aesthetic preferences have been based on an assumption that aesthetic development involved a gradual progression towards an appreciation of art that foregrounded expressive qualities and marginalised aesthetic appeal (Parsons 1987). The focus of the current study emerged from a concern that art educators have overlooked opportunities to understand the diversity of children's aesthetic preferences. Moreover, they have underestimated how images can encourage and enable children to articulate their individual perceptions of their physical, social and cultural worlds.

The study involved 51 children in two English primary schools. Children were asked firstly to find images to represent their ideas of beauty, and secondly to take photographs they thought were beautiful, which they later shared during a series of group interviews. Elsewhere I have explored how children's contributions to these interviews provided evidence of their 
levels of engagement with beauty, and of their diverse perspectives on its meanings (Watts 2018). This article focuses solely on children's images and the evidence they provide of children's aesthetic preferences. In doing so, it seeks to make an original contribution to existing knowledge in the field. Authors of previous studies have focused exclusively on children's responses to paintings and concluded that young children have a relatively narrow range of aesthetic preferences, limited to bright colours and realistic representations of familiar subjects. The findings of the current study suggest authors have underestimated the diversity of children's aesthetic preferences. The article offers evidence that social, geographic and cultural environments may shape children's aesthetic preferences and that images offer children a unique way to 'voice' their social and cultural identities.

The study explored two questions: How do children represent their perceptions of beauty? And How does their social, cultural and geographical environment influence children's aesthetic preferences? In the context of the study, the term 'environment' was inclusive not only of children's geographical locations but also of their social and cultural worlds. The design of the study was innovative in two respects. Firstly, it took advantage of children's increased levels of access to digital technologies and their confidence in using them independently. Rather than respond to a researcher's selection of existing images, children were provided with opportunities for to locate and create their own, and to choose those they wanted to share during a series of group interviews. In response children found and photographed over 600 images that represented their different tastes, interests and preferences. Secondly, the study was carried out in two contrasting environments, one in inner London, the other in a rural village 40 miles from the capital. The contrasts between the schools were geographical but also social, economic and cultural. While one was situated in an affluent village with an almost uniformly white, middle-class population, the other represented the far more diverse, multicultural demographic of the urban environment. Consequently, the study not only explored evidence of the diversity of children's aesthetic preferences, but also of how environmental factors may influence these preferences.

The article begins by reviewing two areas of existing research, namely (i) previous studies of children's responses to artworks and (ii) recent studies of their intentions as photographers. It goes on to describe relevant aspects of the methodology, before analysing the subject matter and visual qualities of the images children found and photographed, and it concludes by reflecting on how the study offers a model for both researchers and teachers to develop a richer understanding of children's interests, preferences and experiences.

\section{Background}

\section{Children's responses to artworks}

Since the term 'aesthetic' is used throughout this article, it is useful to begin with some brief reflections on the term. While it literally means 'things perceived by the senses', aesthetics has traditionally been associated with the philosophy of art and judgments about beauty. It has also acquired associations with everyday life. In Art as Experience (1934) Dewey asserted that aesthetic awareness is one of the 'basic vital functions' shared by humans $(1934,19)$, and that aesthetic experiences occur naturally through interaction with the world. Similarly, Eisner (2002) argued that art education should help students to appreciate aesthetic experiences in everyday life, suggesting that 'the world at large is a potential source of delight and a rich source of meaning if one views it within an aesthetic frame of reference' (2002, 44-5). Whereas UK art educators tend to use 'aesthetic' to refer specifically to visual properties of 
works of art, craft or design, those in the US use the term more broadly to refer to the understanding and appreciation of art; Parsons and Blocker, for example, define aesthetics as 'the analysis of the ideas with which we think about the arts' $(1993,73)$. Perhaps as a consequence of this - most research in the field into has been carried out in the US - authors have tended to make judgments about aesthetic preferences by focusing on viewers' responses to works of art.

The most influential study of children's aesthetic development was carried out by Michael Parsons (1987). Parsons questioned several hundred children (and adults) about artworks in order to find out what they thought and felt about them and how their responses changed as they grew older. He proposed that people progressed through a sequence of developmental stages of aesthetic response. At Stage 1, children demonstrate a minimal awareness of others' preferences and believe artworks are made purely to please the viewer; at Stage 2, they are primarily concerned with subject matter and realism, and whether or not an artwork is beautiful. As they progressed through further stages, Parsons noted that young people placed more value on the expressive qualities of artworks, artistic decision-making and the concepts and values embodied in artworks. Responses that reflected on the beauty of artworks were, Parsons concluded, relatively superficial in nature. Children perceived that the beauty of an artwork depended solely upon its subject matter; they assumed 'a painting will be beautiful if it is about a beautiful subject. Beauty is transferred, as it were, from the subject to the painting' $(1987,40)$.

While Parsons' study offers insights into the nature of children's responses to artworks, methodological issues mean it provides an incomplete picture of children's aesthetic preferences. Firstly, all images Parsons selected for his study were paintings. Children may have been intimidated by their interviewer's art historical knowledge and worried they should provide 'correct' responses to questions. Secondly, the paintings represented a relatively narrow range of styles and subject matter. Parsons' emphasis on $20^{\text {th }}$ century Expressionist paintings seems designed to challenge his participants' preconceptions of art, rather than enable them to reveal their aesthetic preferences. Finally, as he was principally interested in how people's responses to artworks change, Parsons chose to focus on a wide age group but a narrow range of respondents: descriptions of participants' backgrounds suggest a lack of social and cultural diversity. These issues reveal the underlying motivation of the study, namely the belief that teachers should challenge children's perceptions of the types of images that could, or should be used to raise levels of engagement with art.

When researchers present a wider range of artworks to children their responses can be illuminating. Lin and Thomas (2002) found children were more likely to engage with artworks if they had personal or historical associations with their subject matter, while Danko-McGhee's (2006) study, in which she explored young children's responses to artworks and artefacts in a museum, was innovative in that she identified favourite pieces by monitoring the lengths of time children spent looking at each one. Given a broader range of artefacts to select from, children demonstrated diverse preferences, though they were still restricted by location, with no opportunities to look beyond the museum's collection to choose images that held personal meanings or associations for them.

The notion that we can understand the nature of children's aesthetic preferences through judging their responses to artworks is now, arguably, outdated. Artists make work for many reasons, but rarely to please children. Aside from illustrators, there is no equivalent of the children's author, an artist who deliberately creates work with the intention of appealing to younger viewers. Children often find artworks confusing, challenging or intimidating, and can struggle to articulate responses to them - particularly when interviewed by people they perceive to be experts. 
In fairness to authors of previous studies, there were practical as well as philosophical reasons why they chose to focus on artworks. In a pre-digital age, participants had few opportunities to locate their own images and even fewer to use cameras to create them. Nonetheless, their approach could be characterised as a deficit model, in which children are conceptualised as 'works in progress', gradually acquiring knowledge and skills to make 'mature' responses. As such, these studies may have underestimated the diversity of children's aesthetic preferences, and undervalued children's voices.

Authors of recent studies in psychology have adopted alternative approaches to exploring aesthetic preferences. Some use 'preferential looking' tasks to measure babies' responses to images and objects (Krentz and Earl 2013); some explore gender variations in colour preferences (LoBue and DeLoache 2011) while others investigate the stability of aesthetic preferences over time (Pugach, Leder and Graham 2017). (For a recent overview of literature in the field, see Palmer, Schloss, and Sammartini 2013). None, however, take advantage of the increased accessibility of photography and the opportunities it offers to understand children's aesthetic preferences.

\section{Children as photographers}

Two decades ago, cameras were rarely seen in schools. By 2016, two-thirds of 5-15-year-olds in the UK used digital devices to create images; $71 \%$ of 11-year-olds owned smartphone cameras while $90 \%$ regularly accessed images online (ONS 2017; Statista 2017; Ofcom 2016). Children not only take photographs, they also share them: a recent survey of $1,027 \mathrm{UK}$ children revealed that half of 10-12-year-olds share images on Facebook, $40 \%$ on Instagram and $28 \%$ on Snapchat (Graham 2016). Photography has also become increasingly prominent in social research (e.g. Banks 2001; Rose 2007; Emmison, Smith and Mayall 2012). Several authors explore the growing presence of photography in art education (e.g. Stanley 2003; Clover 2006; MacDonald 2012), while early childhood educators widely regard photoelicitation techniques as a valuable means of understanding children's perspectives (e.g. Dockett, Einarsdottir and Perry 2017).

Participant-led photography became accessible as a research method with the advent of disposable cameras in the 1990s. In an early study Aitken and Wingate (1993) explored children's perceptions of their identities within their local environments by accompanying them on 'photo-journeys'. Certain aspects of their project are particular relevant to my own, in that they (i) compared images created by children from contrasting backgrounds and (ii) consciously gave children ownership over their photographs, explaining their methods 'empower[ed] children's fascination with images' (1993, 66). Aitken and Wingate found, however, that the meanings of children's photographs could only really be understood in conjunction with the commentaries they later provided during interviews. Children's images acquired deeper meanings when viewed alongside their explanations of the contexts in which they were taken.

Other authors have used photography to reveal the contrasting visions of different cohorts of children. Luttrell (2010) sought to understand children's perceptions of diversity and found those from disadvantaged backgrounds were likely to hand cameras to others so they themselves could feature in the photographs. Her findings not only anticipate the arrival of the 'selfie generation' but also, as she notes, echo an earlier study by Chalfen (1981), who found young people from poorer backgrounds wanted to appear on-screen, whereas those from middle-class homes used the filming process as a medium for self-expression.

In an international study Sharples, Davison, Thomas and Rudman (2003) sought to understand children's behaviour and intentions as photographers. They provided 180 children 
with cameras to photograph whatever they liked, before analysing the images and interviewing children about them. They found that 7-year-olds photographed their home environment, family and possessions and 11-year-olds photographed animals and the outdoor environment, while 15-year-olds often posed friends for photographs. Sharples et al note factors that influenced outcomes - younger children have less freedom to explore beyond their homes, while teenagers are more likely to integrate photography into their social lives before concluding that children's photographic behaviour can be viewed variously 'as an aesthetic experience, as a socio-cultural activity and a cognitive-developmental process of increasing control over oneself and others' $(2003,13)$.

The significance of this research to the current study lies partly in its scale but also in its design. Specifically, the notion of children taking control of the process of making and sharing images was central to the design of my study. By allowing participants to generate images autonomously, Sharples et al enabled children to represent the diversity of their interests, experiences and preferences. The study was underpinned by the principle that children's intentions, practices and preferences as photographers can be best understood when adults offer minimum intervention in the process, leading the authors to conclude that children are not 'simply apprentice adult photographers, but exhibit distinctive intentions and products that vary with age' $(2003,1)$. Children's voices, they argue, are present in their photographs.

Surprisingly, Sharples et al carried out no further research into children's intentions as photographers. Since the publication of their study, the role of photography in children's lives has changed beyond recognition. Children are no longer dependent upon adults to provide access to cameras, and their motivations for making photographs have evolved as their opportunities have increased. Photography offers children a means of communicating directly with each other, an opportunity to edit their worlds in ways that enable them to illustrate those aspects of their lives that are meaningful to them, and to share their experiences. Authors continue to explore ways in which photography (and video) can enable children to play a more central role in sharing their experiences. Writing recently in this journal, Meager (2018) describes how he provided 10 and 11-year-old children with video cameras to document their experiences of making art, while his concluding comments in another recent (2017) article could also apply to photography as a research tool. Through facilitating opportunities for children to use video, he argues, researchers can explore:

[...] Questions about children's viewpoints and sensibilities; questions that require access to knowledge that only children can have; questions that are best answered in collaboration with children as co-researchers; questions that are about aesthetic and ineffable qualities and values, and questions that require the fullness of intellectual, emotional and sensory experience, especially visual experience, to be answered.

Meager 2017, 18

These questions are child centred, rather than subject centred; they foreground children's own questions, interests and experiences, rather than those of art educators. They are also the kinds of questions I set out to answer when I conceived my own study: How do children represent their perceptions of beauty? How does their social, cultural and geographical environment influence children's aesthetic preferences? 


\section{Methodology}

\section{Overview}

The study involved 51 children in two English primary schools. Children were asked firstly to find images to represent their ideas of beauty, and secondly to take photographs they thought were beautiful. This article focuses specifically on images children generated in response to the research tasks, and the evidence they offer of their aesthetic preferences. However, I draw on one aspect of the interview data, in terms of the brief descriptions of their images children provided as they presented them. While these descriptions often prompted group discussions, an analysis of these discussions is beyond the scope of this article and is presented elsewhere (Watts 2018).

\section{Participants}

From the beginning of the study I wanted to find out whether children's environments influenced their aesthetic preferences. I had few assumptions about the nature of children's preferences; I speculated that, while it would be interesting to find the preferences of children in one location were different to those in another, conversely it would be equally interesting to find that they were similar. I taught in inner London primary schools for 12 years before leaving the city and moving to a rural area. From a personal perspective, I wanted to understand more about two communities of children, and how they could use images to illustrate connections and contrasts between them. In my role as a lecturer in teacher education I worked in partnership with schools in various locations, which enabled me to approach two that were located in contrasting social, cultural and geographic environments.

51 children from two schools took part in the research, 28 from a west London primary school, 21 from a rural village junior school (Fig. 1). Having supported trainee teachers in both schools over a period of years I was aware of the contrasts between them, some of which can be illustrated through pupil statistics. In the London school $68 \%$ of children were eligible for 'pupil premium' funding for disadvantaged pupils, compared with a national average of $27 \%$. Its population reflected the cultural diversity of the area, with $52 \%$ of children learning English as an additional language (NALDIC 2012). At the rural school only $6 \%$ of pupils received premium funding and only $2 \%$ were learning English (NALDIC 2012). I was aware of the broader debates surrounding inequality in the UK (e.g. Belfield, Cribb, Hood and Joyce 2014) and understood children in the London school were perceived as disadvantaged compared with those in the rural school, where pupils typically came from higher-income families and progressed to high-achieving secondary schools in the state and private sectors. Children in the rural school were aged 9-10, while those in London were 1011 and in their final year of primary school. Secondly, a pilot study with 12-14 year-olds suggested children of this age were more inclined to collaborate when choosing images rather than make independent choices, while in a further pilot study 9-11-year-olds carried out the tasks independently.

Fig. 1 Aerial views of the two school locations

Imagery (C) 2018 Google Map data.

\section{The research tasks}

For the first research task I asked children to find images to 'represent your idea of beauty'. In asking this I did not assume children had pre-determined ideas about beauty; rather, I aimed 
to use language accessible to them. The phrase 'your idea of beauty' emphasised that I wanted them to work independently and without influencing each other. I presented the task clearly and aimed to influence children's responses as little as possible. I provided concise printed instructions, envelopes for printed images and blank CDs for digital files. I offered to scan and return original images and sent letters to parents and carers inviting them to discuss any concerns they may have, while requesting that they provide help with the tasks if asked but to avoid influencing children's decisions.

For the second task, I loaned children digital cameras for a week, and asked them to take photographs they thought were beautiful. Whereas participants in earlier studies (e.g. Sharples et al 2003; Luttrell 2010) were restricted to using single-use film cameras, I gave children digital cameras that enabled them to review and edit their images before deciding which they wanted to share. Again, I provided minimal instructions and, though I offered to demonstrate how to use the cameras, it was apparent children needed little support.

\section{Ethical issues}

I aimed to provide as much clarity and reassurance about the research process to children, teachers and parents. Aware that researchers should gain participants' confidence, I gained children's trust through a series of weekly classroom visits, during which I supported their learning across the curriculum. These visits enabled me to get to know children informally, and to become familiar with each teacher's classroom routines and strategies for managing behaviour. I was sensitive to teachers' needs and interests. One, for example, was interested in raising standards in literacy, and visualised the project as an opportunity for children to gather visual resources to inspire their writing. Aware that a project involving photography could raise concerns I wrote to parents, explaining the project aims, its methods and the nature of their children's involvement. I sent parental consent forms, invited them to meetings to discuss the research and gained permission to publish images children found and photographed. I offered children the option of sharing their images or simply handing them to me, and assured them they could withdraw from the project at any point if they chose. At the end of the project I shared data and findings with teachers at both schools.

\section{Interpreting children's images}

My approach to interpreting children's images drew upon previous studies such as Parsons (1987), in that I was interested not only in the subject matter depicted in children's images, but also in the visual qualities they featured. I anticipated that children might find or photograph images representing similar subjects yet choose examples with distinctive visual qualities. A child who photographed a stormy sky, for example, might have different aesthetic preferences to one who photographed the same sky at sunset.

My approach to interpreting the subject matter of children's images drew on Rose's (2007) four stages of content analysis: finding images; devising categories; coding images and analysing results. The children themselves carried out the first stage of the process, while for the second stage I devised categories to code images and carried out the coding process several times. This informed the final stage of the process, in which I created a quantitative summary of the image contents, foregrounding the most frequent subject matter before (i) identifying characteristics, (ii) highlighting trends and (iii) exploring similarities and differences between image sets. While this part of the process was relatively clear-cut, that of analyzing and summarising the visual properties proved less straightforward, as I was aware of the subjective element in the process of deciding upon the defining characteristics of an image

The 51 children found and photographed 632 images to represent their perceptions of beauty. The remainder of this article reflects firstly on how these images offered evidence of 
the diversity of their aesthetic preferences, in terms of the subject matter and visual properties of their images and secondly on evidence of how children's social, cultural and geographical environments appeared to influence their aesthetic preferences.

\section{Children's images of beauty}

\section{Table 1 Content analysis of found images}

* There were 28 participants in the urban school and 23 in the rural school; therefore one child in the urban school is equivalent to $3.5 \%$ while one child in the rural school is equivalent to $4.5 \%$.

Table 2 Content analysis of photographs

\section{Subject matter}

Children's images depicted a wide range of subject matter including people, landscapes, plants, animals, architecture, imaginary worlds and abstract patterns. There was also diversity within each category: images of people ranged from family celebrations to famous celebrities while images of landscapes ranged from vast, remote panoramas to calm, sunlit scenes. Pictures of plants ranged from delicate roses to ornamental lettuces while those of animals ranged from butterflies to cats, dogs, giraffes, bears, tigers, dolphins and whales. While most children chose images representing the natural world, others opted for intensely coloured illustrations of fantasy worlds, or equally colourful images of distant parts of the solar system. The range of children's aesthetic preferences was more complex and more diverse than authors of previous studies had concluded, as illustrated by the composite images on these pages.

Fig. 2 The London school: children's found images

Fig. 3 The London school: children's photographs

Fig. 4 The rural school: children's found images

Fig. 5 The rural school: children's photographs

Fig. 6 Photograph by Anya, rural school

Fig. 7 Found image by Ammar, urban school

Fig. 8 Photograph by Mohad, urban school

Fig. 9 Image from video by Ammar, urban school

Fig. 10 Photograph by Kamaudin, urban school

Fig. 11 Photograph by Kamaudin, urban school 


\section{Visual properties}

While children's images revealed how they found beauty in different subjects, they also suggested their awareness of the visual properties of images such as colour, light and pattern. As described above, previous studies of aesthetic preferences concluded that colour is particularly important to children, and many of the images children found for the current study confirmed this. Whether they located them online, in books or magazines, children often chose intensely coloured images while, even in the depths of an English winter, several managed to find and photograph bunches of brightly coloured flowers.

However, in their descriptions of their images, children rarely identified colour as the only reason why an image was beautiful and usually mentioned it in conjunction with other qualities or associations. Ilham, for example, described how she found her image, of pink waves crashing on to a beach, beautiful because of its colours but also because of her memories of arriving on the beach with her family and taking the photograph. Similarly, Anya explained her photograph of her teddy bear collection (Fig. 6) was beautiful because it was 'really colourful' but also because the scene 'makes me feel peaceful and homely and it's things I love'. Ammar admired how the colours in his image (Fig. 7) were 'like a rainbow' but added that the way 'the bit of water... reflects it... makes it look even more beautiful'. While children found beauty in colour, they usually perceived it as only one of several visual qualities that could combine to make an image beautiful to them.

Light was an equally prominent feature of children's images. Several children introduced their images by referring to how light illuminated landscapes or leant images atmospheric qualities. Rafeeah explained she chose her image of the 2012 Olympics closing ceremony 'because of the lights... and the fireworks', while Mohad described how his photograph of the Thames (Fig. 8) was beautiful because 'of how the sun bounces off the river'. Ammar introduced a photograph he had taken of light streaming through a bedroom window (Fig. 9) as being 'like a passage to a new world! Maybe angels could live in there!', and Mustafa described how his image of a surreal landscape 'makes me feel sad a bit... because of the moonlight effect and it's dark... And then it makes me feel happy because of the flowers and the sparkly stuff'. Yet despite the luminosity of many of their images, children referred to light less often than colour; they seemed to take light for granted: it was always present, yet rarely noticed.

Aside from colour and light, children were also drawn to patterns. In particular, children found beauty in symmetrical patterns, whether they appeared in the natural world, in designs or digitally manipulated images. Some, like Fartun, photographed patterns they found on fabrics at home, while others, such as Ammar chose abstract images with reflected or repeated patterns. Yasmina found more images than almost any other child, several of which featured digitally manipulated symmetrical compositions. Composition was another striking feature of children's images, such as those photographed by Kamaudin, which feature a pattern of shadows cast by a fence (Fig. 10) and a shadow on a brick wall (Fig. 11). 'I saw the shape and I thought it was so beautiful', Kamuadin explained, suggesting that he was aware of the strength of the composition of the image.

Children sometimes revealed their awareness of how visual features could subtly affect the aesthetic appeal of images. Yonis brought an image to school but lost it (it later emerged that another boy had stolen it). He had located the image online and I invited him to find it again, and I watched as he typed 'beautiful flowers' into a search engine and spent several minutes scrolling through hundreds of similar thumbnail images, before finally selecting one. This scene provided an unexpected insight into how children used search engines to complete the task. The speed with which they were able to access online images 
enabled them to 'fine tune' their choices, to ensure their choices represented the precise idea of beauty they were seeking. The scene also illustrated how seriously children took the task. These children were discerning and, while they searched for particular subject matter in images before turning their attention to their visual properties, both were important to them. Children's sensitivity to the subtle differences between images may also account for the fact that, of the 139 images they found for the study, only two were identical.

\section{Contrasting aesthetic preferences}

As described above, I deliberately located the study in two contrasting environments in order to find out whether there was any evidence that children's environments influenced their aesthetic preferences. My content analysis revealed some similarities between the two image sets. The natural world, in the form of landscapes, flowers and animals, frequently featured in the images children found and photographed, with water being a particularly prominent feature. A third of children in both schools photographed aspects of their local environment and around a fifth found images of flowers. One in ten children from each school chose to share images of buildings in distant locations while a similar proportion shared images of celebrities. However these similarities were outweighed by contrasts between the two sets of images, in terms of both their subject matter and visual properties.

Fig. $12 \quad$ Children in the rural school found beauty in nature

Fig. $13 \quad$ London children preferred manipulated images of nature

Fig. $14 \quad$ Children in London often chose to share images of people

Firstly, children in the rural school often found beauty in nature (Fig. 12). They were twice as likely to find or photograph images of nature than those in London: half chose images of animals, compared with one in five in London, while two thirds photographed animals compared with one in five in London. $60 \%$ of rural children found images of landscapes compared with only $30 \%$ of London children, and $30 \%$ photographed landscapes compared with $15 \%$ in London. It is perhaps unsurprising that children's direct experience of the natural environment influences their perception of it as beautiful. It could be argued that children in London had less access to nature, therefore the natural word featured less prominently in their images. However, there were several parks within a few minutes' walk of the school, as well as the nearby Thames, which only one child photographed.

Secondly, whereas rural children found beauty in images that faithfully represented the natural world without distorting or idealising it, London children preferred images of nature that had been digitally edited, enhanced and manipulated (Fig. 13). Children in both schools shared images with rich, vivid colours and, superficially, the two image sets featured similar colours. However, although many children in the rural school chose intensely coloured images, they were always accurate representations of subjects that were naturally strongly coloured - a view of Ayers Rock, for example. Though visually striking, few were digitally manipulated. In contrast, more than half of the images of nature found by London children were digitally enhanced, with exaggerated natural forms, heightened tonal contrasts and intensified colours. Similarly, $80 \%$ of images of flowers chosen by London children were digitally manipulated, compared with only $25 \%$ of those chosen by children in the rural school. One way of interpreting this data is that, for the urban children, visual impact mattered more than accurate depictions of subject matter; they more concerned with the intensity of the images rather than their integrity. 
Thirdly, there was a marked difference in the way children represented people in their images. Children in London often chose images of people to represent their ideas of beauty (Fig. 14); a third shared images of themselves, while 10\% chose images of their mothers and another 10\% siblings or cousins. People featured even more frequently in their photographs: a third photographed themselves while a fifth photographed siblings or cousins. In contrast, rural children rarely pictured people. Only two shared images of themselves or family members, while only five photographed people, who appeared in only one of the 41 images found by boys and in only five of their 59 photographs, while of the 187 images girls photographed only ten included people. As such, the urban children's responses to the task were similar to those reported by Luttrell (2010) and Chalfen (1981), who found that children from disadvantaged backgrounds were much more likely to photograph themselves and their families.

Why was this? When children chose images to represent their experiences of beauty that had social and emotional associations for them, it would seem they were responding in much the same way as the Parsons' (1987) youngest participants who, at what he judged to be 'Stage 2' of aesthetic development, were concerned principally with the subject matter of images. They were untroubled by blurred, pixelated or haphazardly composed photographs. What mattered to them was the subject, not the way it was represented. However, I would suggest the urban children also associated beauty with loved ones for a more complex reason. These children found and photographed their images during the first term of their final year in primary school, and were anticipating moving on to secondary school. I suspect they were drawn to images that represented continuity during a period of change. Consciously or otherwise, these children may have found beauty in images of loved ones because these images helped them to define themselves to their peers. Children regarded the process of selecting, sharing and photographing images as an opportunity to assert their identity within their peer group and to reveal aspects of their home lives that might otherwise remain hidden. Therefore their social environment, which they anticipated was about to change, may have influenced what they perceived to be beautiful.

These children seemed oblivious to any aesthetic imperfections of their family photographs. In her recent exploration of the impact of digital technologies on family photography, Rose (2014) reflects on how people are unconcerned by such technical deficiencies in their family photographs, because they perceive them less as beautiful images and primarily as social artefacts: 'Family photography does not consist just in a certain kind of photograph. Rather, it is a social practice' (Rose 2014, 71). On reflection, this is much the same message children in the urban school were telling me, whether it concerned the memory of a distant beach on a family holiday or the love they felt for family members, present or absent. They were developing their awareness of the potential of images as a form of social currency, artefacts that could communicate those aspects of their lives, beautiful or otherwise, they chose to share. Being asked to find and share an image they thought was beautiful became a trigger that started the process.

There was also evidence that individual children had consistent aesthetic preferences. Several London children chose to re-photograph existing images, often those displayed in their homes. There are several possible reasons for this. Some children in Luttrell's (2010) study re-photographed existing images because they depicted absent family members, and children in London may have had similar motivations. Others may simply have been pleased with the image they chose for their first task and chose something similar to photograph for their second. However, the tendency to re-photograph images may also suggest these children's aesthetic preferences remain consistent in different contexts, and they were drawn to images that featured particular subject matter or visual properties. 
This explanation becomes more plausible when we look at images individual children found and photographed. Some photographed aspects of their local environment that echoed the subject matter or visual properties of their found images. Ilham, for example, found images that featured soft, organic shapes of flowers, waves and mosques, before taking a sequence of 14 photographs of plants in her local park. Rafeeah photographed a nearby tower block, before re-photographing existing images of a Trafalgar Square lion, the 'Gherkin' building and the tail of a submerged humpbacked whale. Despite their diverse subject matter, a looming monochromatic shape dominated each image.

Finally, as well as analysing what was present in children's images, I also noted what was absent. There was very little evidence of gender influencing aesthetic preferences and even less that children were influenced by media images of beauty. Although people frequently featured in the images found and photographed by children in the urban school, celebrities never featured among them. In the rural school, people rarely featured in children's images. One girl, however, chose an image of Jo Brand while her friend chose an image of Miranda Hart. Brand and Hart are both high profile public figures in the UK, widely praised for their refusal to conform to gender stereotypes. It is hard not to speculate that these girls were aware that they were confounding the expectations of their social group when they chose their images, deliberately taking the opportunity to make visual statements that challenged conventional notions of beauty.

This is an example of how, while children's images provided evidence of their aesthetic preferences, they could provide only a partial explanation of their broader experiences of beauty. This article has focused on the subject matter and visual properties of the images children found and photographed. As I have described elsewhere, children went on to share their images during a series of group interviews in which they explained their choices, responded to each other's images and reflected on their broader experiences of beauty (Watts 2018).

\section{Conclusions and implications}

There are two main findings of this study. Firstly, the images children found and photographed for the study depicted a diverse range of both subject matter and visual properties. When they searched for images to represent their perceptions of beauty, children focused initially on subject matter before turning their attention to the visual properties of individual images. Secondly, the findings suggest that environmental factors may influence children's aesthetic preferences. Children in the rural area often photographed landscapes, flowers and animals, suggesting their direct experience of nature influences their perception of it as beautiful. Those in London preferred images of nature that were digitally generated or manipulated, a practice the rural children judged to be problematic. And while London children often chose images of family members to represent beauty, rural children rarely selected images that depicted people.

Given the relatively small number of children involved in the study, further research is needed in order to determine the extent to which its findings are representative of broader populations. It is hoped that teachers and researchers will replicate or adapt the design of the study to further explore children's aesthetic preferences. The study offers teachers a model for using images to help children reflect upon their personal identities and experiences, and researchers a model for comparing the aesthetic preferences of children in contrasting communities. Similar methods could be used to explore other themes. Images can provide children with starting points from which to investigate, reflect upon and communicate a wide range of aspects of their lived experiences. The ease with which children can independently 
locate and create images offers opportunities for teachers and researchers to develop a deeper understanding of their interests, ideas and perspectives. As Meager concludes, cameras 'reveal aspects of their lives that only they, as children, are in a position to share' $(2017,18)$.

There is a memorable scene in the film Kes (1969) that illustrates the moment when a child creates a connection with others through sharing what is meaningful to him. Until this point in the story, Billy Casper has spent much of his time in school slumped on his desk, disconnected from lessons that seem meaningless to him. He is pre-occupied with an injured kestrel he is nurturing at home, training it with the help of library books. In a pivotal scene, Billy's teacher asks him to tell the class facts about himself. After some cajoling from other pupils, Billy moves to the front of the class and describes in loving detail how he has trained his kestrel, holding everyone's attention as he immerses them in his experience. The scene represents a transformative moment for Billy. It is as if he is recognised by his classmates for the first time. Though the scene is entirely Billy's, the teacher's role is crucial one. He realises Billy has something valuable to share, and senses the opportunity to change perceptions of him.

If this scene were set in a school today, Billy Casper would probably illustrate his talk with a PowerPoint presentation, or by taking his smartphone from his pocket and sharing digital photographs with the class. Billy would know that images offer a unique way of engaging children. An image can become the first line in a conversation with a child and enable them to articulate experiences, thoughts and ideas that might otherwise remain unsaid. As educators we should be curious about children's experiences, and provide them with opportunities to communicate their responses to the visual world and to 'voice' their social and cultural identities. The images children found and photographed for this study not only help us to understand their aesthetic preferences, they also demonstrate the depth of their engagement with the visual world.

The author would like to express thanks to PhD supervisors Professor Rachel Mason and Dr Victor Durà-Vilà for their valuable contributions to this research, and to Art Projects for Schools for supporting the funding of the study.

\section{Author's footnote}

As described above, many children shared images they found online. As these images are widely available on various websites it has proved impossible to track down to track down copyright holders. Figures 4, 7 and 13 are the author's digital re-creations based closely on children's original images. 


\section{References}

Aitken, S.C. and Wingate, J. 1993. "A Preliminary Study of the Self-Directed Photography Of Middle-class, Homeless, and Mobility-Impaired Children." The Professional Geographer 45 (1): 65-72.

Banks, M. 2001. Visual Methods in Social Research. London: Sage.

Beech, D. (2009) Art and the Politics of Beauty in D. Beech, (Ed.) Beauty London: Whitechapel Gallery.

Belfield, C., Cribb, J., Hood, A. and Joyce, R. 2014. Living Standards, Poverty and Inequality in the UK: 2014. (No. R96) IFS Reports, Institute for Fiscal Studies.

Chalfen, R. 1981. “A Sociovidistic Approach to Children's Filmmaking: The Philadelphia Project." Studies in Visual Communication 7 (1): 2-32.

Clover, D.E. 2006. "Out of the Dark Room: Participatory Photography as a Critical, Imaginative, and Public Aesthetic Practice of Transformative Education." Journal of Transformative Education 4 (3): 275-290.

Danko-McGhee, K. 2006. "Favourite artworks chosen by young children in a museum setting." International Journal of Education Through Art 2 (3): 223-235.

Dewey, J. 1934 Art as Experience

Dockett, S., Einarsdottir, J. and Perry, B. 2017. "Photo Elicitation: Reflecting On Multiple Sites Of Meaning." International Journal of Early Years Education 25 (3): 225-240.

Eisner, E. 2002. The Arts and the Creation of Mind. New Haven CT: Yale University Press.

Emmison, M., Smith, P. and Mayall, M. 2012. Researching the Visual (Second Edition). London: Sage.

Graham, R. 2016. Safer Internet Day 2016 - Staying Safe Online. Accessed December 17, 2017. http://www.comresglobal.com/safer-internet-day-2016-staying-safe-online/

Herne, S., 2005. "Download: Postcards Home. Contemporary Art and New Technology in the Primary School." International Journal of Art and Design Education 24 (1): 5-19.

Hickey, D. (1993/2009) Enter the Dragon: On the Vernacular of Beauty, in The Invisible Dragon: Four Essays on Beauty pp. 15-24. Los Angeles: Art Issues Press. Revised and expanded edition (2009) Chicago: University of Chicago Press.

Krentz, U. C. and Earl, R. K. 2013. "The Baby As Beholder: Adults And Infants Have Common Preferences For Original Art." Psychology of Aesthetics, Creativity, and the Arts 7: 181-190. 
Lin, S. F., and Thomas, G. V. 2002. "Development Of Understanding Of Popular Graphic Art: A Study Of Everyday Aesthetics In Children, Adolescents And Young Adults." International Journal of Behavioral Development 26: 278-287.

LoBue, V. and DeLoache, J.S. 2011. "Pretty In Pink: The Early Development Of GenderStereotyped Colour Preferences.” British Journal of Developmental Psychology 29 (3): 656-667.

Luttrell, W. 2010. “A Camera Is A Big Responsibility: A Lens For Analysing Children's Visual Voices.” Visual Studies 25 (3): 224-237.

Macdonald, I. 2012. "Why Throw The Negs Out With The Bathwater? A Study Of Students" Attitudes To Digital And Film Photographic Media." International Journal of Art and Design Education 31 (2): 191-211.

Meager, N. 2017. "Children Make Observational Films - Exploring A Participatory Visual Method For Art Education." International Journal of Education Through Art 13 (1): $7-22$.

Meager, N. 2018. "Children As Observational Film-Makers: A Deweyan Approach To Researching Primary School Children's Experience As They Make Art." Education 31346 (4): 411-423.

NALDIC (National Association for Language Development in the Curriculum). 2012. EAL Pupils in Schools. December 14, 2017. https://www.naldic.org.uk/research-and-information/eal-statistics/eal-pupils/

Ofcom (Office of Communications) 2016. Children and Parents: Media Use and Attitudes Report. Accessed December 15, 2017.

https://www.ofcom.org.uk/_data/assets/pdf_file/0034/93976/Children-Parents-Media-UseAttitudes-Report-2016.pdf

ONS (Office For National Statistics). 2017. Internet Access-Households And Individuals. Accessed December 15, 2017: https://www.ons.gov.uk/peoplepopulationandcommunity/householdcharacteristics/ho $\underline{\text { meinternetandsocialmediausage/bulletins/internetaccesshouseholdsandindividuals/2017 }}$

Palmer, Schloss, and Sammartini 2013. "Visual Aesthetics and Human Preference." Annual Review of Psychology 64: 77-107.

Parsons, M.J. 1987. How We Understand Art New York: Cambridge University Press.

Parsons, M.J. and Blocker, H.G. 1993. Aesthetics and Education. Chicago: University of Illinois Press.

Pugach, C., Leder, H. and Graham, D.J. 2017. "How Stable Are Human Aesthetic Preferences Across The Lifespan?" Frontiers in Human Neuroscience 11. 
Rose, G. 2007. Visual Methodologies: An Introduction to the Interpretation of Visual Materials (Second Edition). London: Sage.

Rose, G. 2014. "How Digital Technologies Do Family Snaps, Only Better" in J. Larsen and M. Sandbye (Eds.) Digital Snaps: The New Face of Photography London: I.B. Tauris.

Sharples, M., Davison, L., Thomas, G.V . and Rudman, P.D. 2003. "Children As

Photographers: An Analysis of Children's Photographic Behaviour and Intentions at Three Age Levels", Visual Communication 2 (3): 303-330.

Stanley, N. 2003. "Young People, Photography and Engagement." International Journal of Art and Design Education 22 (2): 134-144.

Statista 2017. Share of Children Owning Tablets and Smartphones in the United Kingdom from 2017, by Age Accessed March 23, 2018. https://www.statista.com/statistics/805397/children-ownership-of-tabletssmartphones-by-age-uk/

Steers, J. (2014) Reforming the School Curriculum and Assessment in England to Match the Best in the World - A Cautionary Tale International Journal of Art and Design Education Vol. 14, No. 2 pp. 6-18.

Winston, J. 2010. Beauty and Education London: Routledge. 